\title{
Prevalence and Associated Factors of Obsessive-Compulsive Disorder in Egyptian Adolescents
}

\author{
${ }^{1}$ Hala M Gabr, ${ }^{2}$ Ayman A Elhadad, ${ }^{1}$ Shaimaa Y Abdel Raouf, ${ }^{1}$ Ghadeer M El \\ Sheikh
}

${ }^{1}$ Public health and community Medicine, ${ }^{2}$ Psychiatry Faculty of Medicine, Menoufia University, Cairo, Egypt.

Submission Date: 17-12-2020Ｒevision Date: 12-01-2021 Acceptance Date: 13-01-2021

\begin{abstract}
Background: Obsessive compulsive disorder (OCD) is a burdensome disorder which is increasingly becoming the focus of interest in adolescent psychiatry due to its impact on the quality of life. Objective: to assess the prevalence and associated factors of obsessivecompulsive disorder in Egyptian adolescents. Method: A nested case control study (cross sectional study followed by case control study) was conducted on 1574 students from Menoufia governorate, Egypt. The participants were selected from secondary schools using multistage random sample. OCD was diagnosed using Yale-Brown ObsessiveCompulsive Scale. Arabic version of the Wechsler Adult Intelligence Scale-IV was used to measure intelligence and cognitive ability in cases with OCD. Results: The prevalence of OCD was $3.24 \%$. There was a statistically significant difference between OCD cases and control, being higher in urban areas (OR 2.43, 95\% CI 1.09-5.43), high socioeconomic standard (SES) (OR 2.95, 95\% CI 1.24-7.06), positive family history (OR $4.40,95 \%$ CI 1.91-10.11) and the absence of close friend (OR 2.22, 95\% CI 1.00-4.91). There was non-significant statistical difference between OCD cases and control regarding total IQ score and verbal IQ, but the performance IQ (PIQ) showed significant difference between the two groups being lower in OCD cases. On logistic regression, the predictors for OCD were high SES, positive family history, absence of close friend and low PIQ. Conclusion: OCD was found to be prevalent among adolescents. Urban residence, high SES, positive family history, the absence of close friend and low PIQ were significantly associated with OCD.
\end{abstract}

Keywords: Obsessive-Compulsive, Prevalence, Adolescent, psychiatric disorder.

Corresponding author: Ghadeer Maher Mohammad El Sheikh E.mail:- ghadeer_maher @yahoo.com

\section{Introduction}

Obsessive-compulsive disorder (OCD) in childhood and adolescence is a potentially disabling psychiatric disorder, associated with extensive impairment of quality of life. ${ }^{1}$ OCD is characterized by obsessive symptoms (repetitive unwanted intrusive thoughts, images, or urges) and/or compulsive symptoms (repetitive behaviors or thoughts). ${ }^{2}$

OCD is now being reported to be more prevalent in the young population than previously, when it was considered rare.
Several epidemiological studies in community samples of children and adolescents have reported prevalence ranging from $0.1 \%$ to $4 \%$., $3,5,6$

OCD often starts in childhood and adolescence and can turn into a chronic disorder $^{7}$; therefore, it is increasingly becoming a focus of interest because it is associated with impairment in the performance of routine daily activities, maintenance of social relationships, and academic performance. ${ }^{8,9}$ 
Despite early onset of OCD being supported by several studies, adolescents do not always receive proper diagnosis. This is due to several reasons. For example, young people hide their fears and rituals, considering them embarrassing and odd. Family members may not give enough importance to the problem or consider symptoms to be excessive, or OCD is mistakenly diagnosed. ${ }^{10}$ So, it is strongly recommended that screening for the presence of obsessive-compulsive symptoms among adolescents should be routinely conducted. ${ }^{11}$ Several disorderspecific measures to assess OCD in children and adolescents have been developed and tested in the past decades. According to the review conducted by Iniesta-Sepulveda et al., in the field of pediatric OCD, there are well-established measures to assess symptoms and severity, one of them is the clinical interview Children's Yale-Brown Obsessive Compulsive Scale (CYBOCS). ${ }^{11}$ Many studies have addressed impairment of a variety of neurocognitive functions such as attention, visuospatial memory and executive functioning in adults with OCD. ${ }^{12}$

Although, there are lots of clinical literatures on OCD, the availability of specific timely and accurate data about its

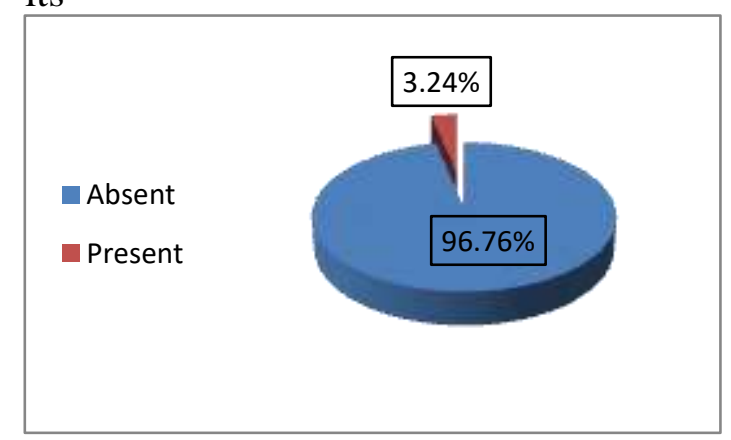

\section{Figure 1 Title: Prevalence of OCD in the studied group}

prevalence in adolescents is still a problem in Egypt. This scarcity of data was the main motivation for the present study. Therefore, the main objective of this study was to determine the prevalence of OCD in secondary school adolescent students in Menoufia, Egypt and to explore its risk factors. A secondary objective of this study was to investigate the intelligence quotient (IQ) in a sample of adolescents with obsessive-compulsive disorder (OCD) and to compare them with healthy controls (HC).This information will help health educators and policy makers to develop proper mental health education programs.

\section{Method}

A nested case control study (cross sectional study followed by case control study) was carried out during the period from October $1^{\text {st }}, 2020$, to December $1^{\text {st }}$ 2020 in Menoufia governorate, Egypt. Approval of the local directorate of education and school administration was obtained. The study protocol was approved by Research Ethics Committee of Faculty of Medicine, Menoufia University, in accordance with the declaration of Helsinki (1975, revised in 2000). A written informed consent was distributed to and assigned by each participant. The survey was carried out among secondary school students enrolled in general and vocational public schools. A pilot study was done on 80 students, (not included in the full-scale study), aiming at testing the validity of the questionnaire and to reveal any modifications or additions needed, and estimating the time needed to collect the required data.

The sample size was calculated using Epi Info (2000) program depending on both the total number of secondary school students in Menoufia governorate which was 66806 students during the academic year (2020-2021) and according to Barzilay et al., who estimated the prevalence of OCD in large community youth sample, and it was $3 \%{ }^{13}$, sample size has been calculated at power $90 \%$ and $95 \%$ CI. So, the calculated sample 
size was 1628 students. Fifty-four students were excluded from the study; 35 students refused to participate and 19 questionnaires were incomplete resulting in a response rate of $96.7 \%$ giving a final sample of 1574 students as participants in this work.



Figure 2: Degree of OCD among the cases.

The eligible participants were selected from the secondary schools of Menoufia governorate using multistage random sample. Secondary schools in both educational zones (eastern and western zones) in Shebin El Kom city as well as the rural sector were included. Two general secondary school for girls and two for boys were randomly selected from each zone as well as one mixed school from the rural sector. Five vocational schools (one commercial school for boys and one for girls; one industrial school for boys and one for girls and one mixed agricultural school) were selected from Shebin El Kom city. This distribution covered all social strata, both sexes, and included both urban and rural sectors of the community. From each selected school, two classes (cluster) from each grade were randomly selected. Enrollment criteria included: (1) age 15 to 18 years; (2) physically and cognitively capable of completing study procedures; and (3) absence of a significant physical condition, developmental delay that impairs cognition (e.g., intellectual disability) or history of psychiatric problems.

The investigators spent about 45 minutes in each class; explaining the confidentiality of the collected data, informing the students about the study, encouraging them to participate and to express their experiences.

Each participant completed a selfadministered questionnaire of two parts. The first part involved a sociodemographic data form, which included questions about age, gender, residence, birth order, family size, questions about Socioeconomic status according to ElGelany, et $\mathrm{al}^{14}$, positive family history, parental conflicts, smoking, drug abuse, presence of close friends (the friend makes them feel good about their ideas, gives them advice, makes them feel important and special, they tell each other their problems, and they get over arguments quickly), chronic diseases and traumatic life events. The second part involved a qualitative assessment to confirm the presence of OCD according to the Arabic version of Yale-Brown Obsessive-Compulsive Scale (YBOCS). ${ }^{15}$

The Yale-Brown Obsessive-Compulsive Scale (YB-OCS) was used to specifically measure the types and severity of symptoms of OCD. It has five items on obsessions and five items on compulsions, each with a score ranging from 0 to 4 , where $0=$ no symptom, $1=$ mild symptoms, 2 = moderate symptoms, $3=$ severe symptoms, and $4=$ extreme symptoms; the maximum total score is 40. The total score ranges of severity for patients who have both obsessions and compulsions are as follows: $0-7=$ subclinical, $8-15=$ mild, $16-23=$ moderate, $24-31=$ severe , and $32-40=$ extreme. The cutoff score for clinically significant symptoms is greater than 16 . The scale was developed by Goodman et al., ${ }^{16}$ and evaluated by Kim and colleagues. ${ }^{17}$ The reliability of the Arabic version was 0.85 while Cronbach's alpha reaches $0.80 .^{18}$

Out of the total sample consisted of 1574 adolescents aged between 15 and 18 years, 51 had been diagnosed with OCD. Equal numbers of participated students 
that are free from OCD are chosen randomly getting a case to control ratio 1:1 to assess the socio-demographic risk factors of OCD and to conduct a specific analysis of IQ.

Table (1): comparison between different associated factors among the studied groups:

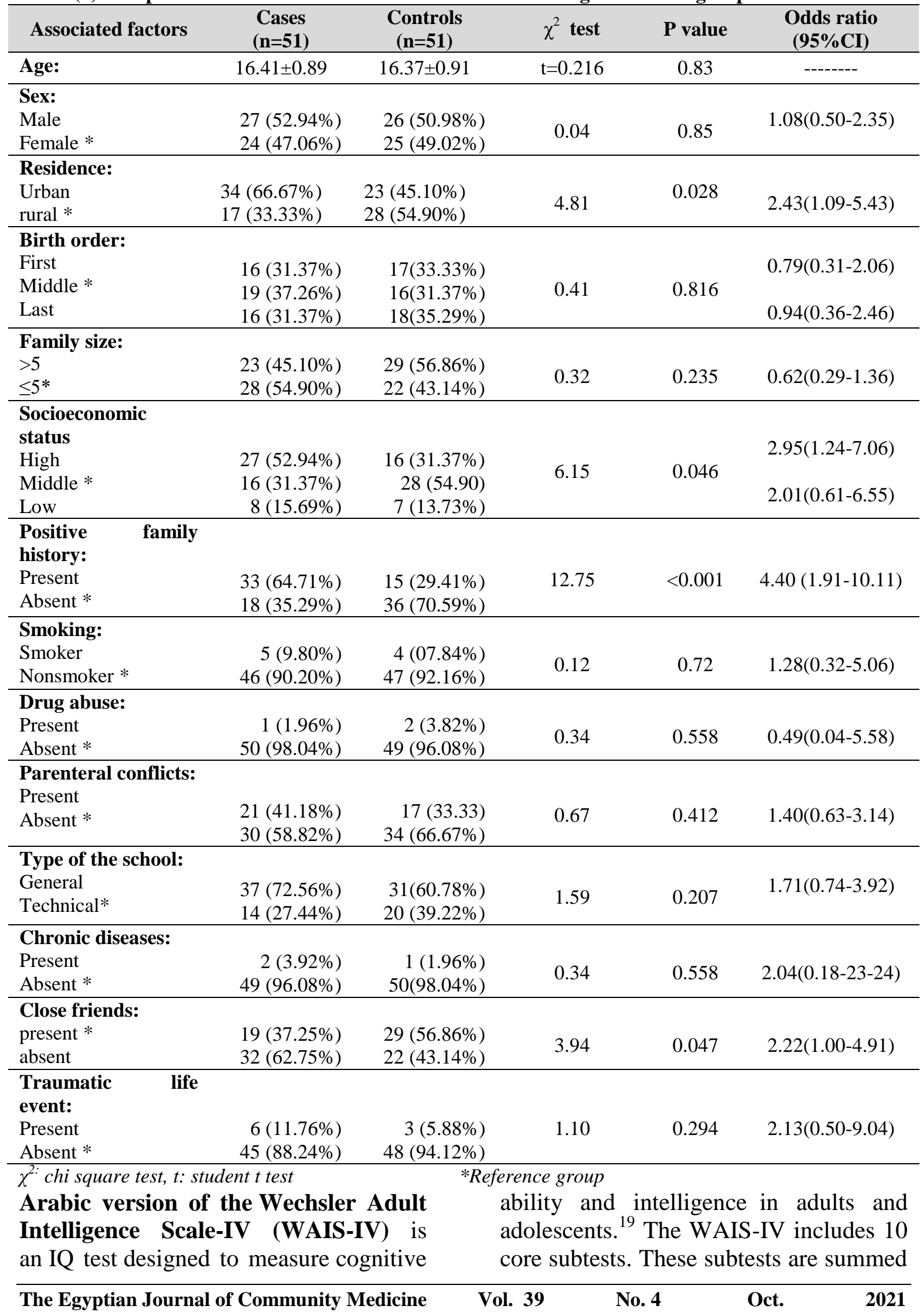


to four indexes (the Verbal Comprehension Index, the Working Memory Index, the Perceptual Reasoning
Index, and the Processing Speed Index). The Full-Scale IQ ranges from 40 (Exceptionally Low) to 160

Table (2): IQ among OCD cases and controls:

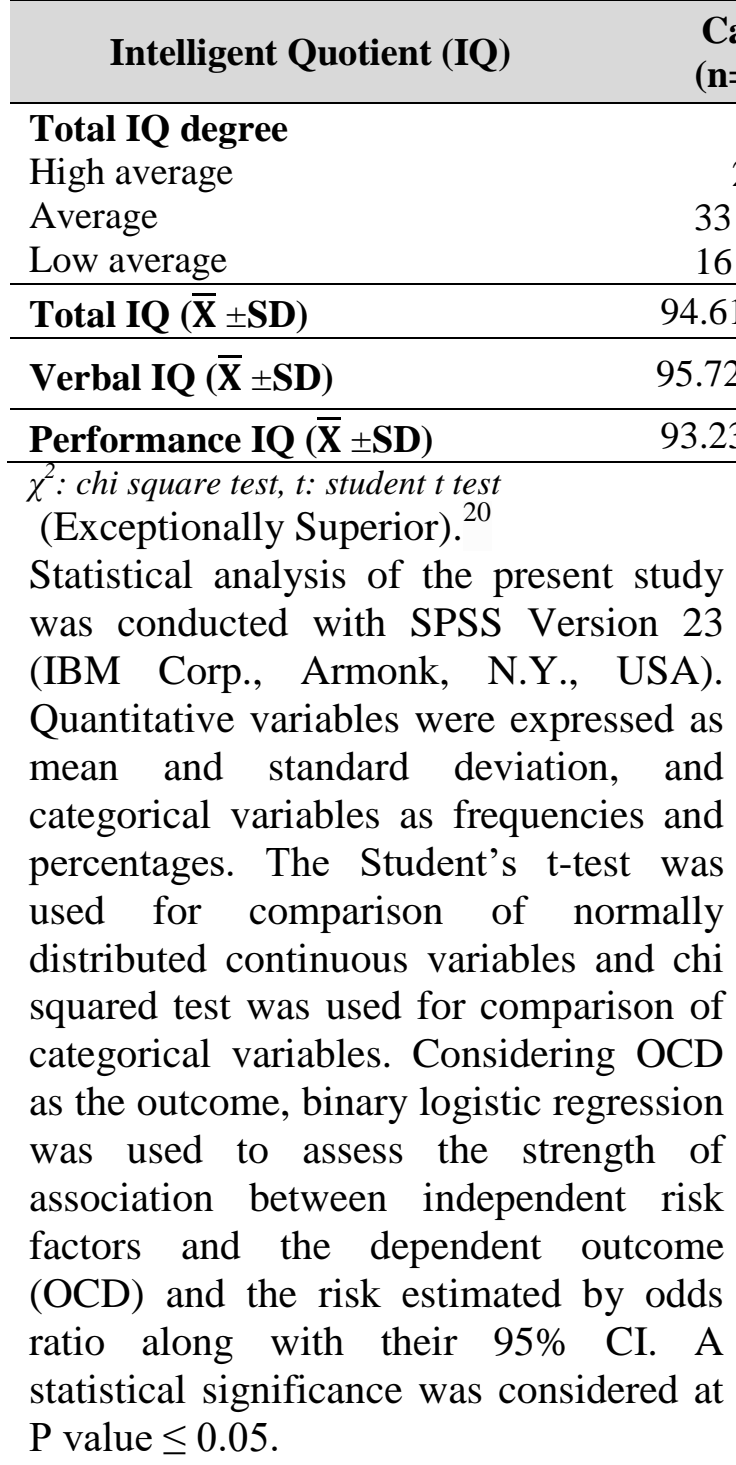

\section{Results}

The Mean age of the studied participants was 16.39 ranging from (15-18 years). Among them, $52.16 \%$ were males, $57.31 \%$ were living in urban areas and $50.57 \%$ of them have middle socioeconomic level.

The prevalence of OCD in the studied participants was $3.24 \%$ (51 out of 1574) (Fig 1). Among the OCD cases 58.82\%, $37.25 \%$ and $3.93 \%$, had mild, moderate and sever degree of OCD respectively (Fig 2).

\begin{tabular}{cccc}
$\begin{array}{c}\text { Cases } \\
(\mathrm{n}=51)\end{array}$ & $\begin{array}{c}\text { Controls } \\
(\mathrm{n}=51)\end{array}$ & $\begin{array}{c}\text { Test of } \\
\text { significance }\end{array}$ & $P$ value \\
\hline
\end{tabular}

$2(3.9 \%) \quad 5(9.8 \%)$

$33(64.7 \%) \quad 35(68.6 \%) \quad \chi^{2}=2.27 \quad 0.321$

$6(31.4 \%) \quad 11(21.6 \%)$

$\begin{array}{cccc}94.61 \pm 8.91 & 96.56 \pm 9.75 & \mathrm{t}=1.05 & 0.29 \\ 95.72 \pm 9.75 & 96.80 \pm 11.46 & \mathrm{t}=0.51 & 0.61\end{array}$


Obsessive compulsive disorder (OCD) is documented as one of the most prevalent psychiatric disorders that are associated with significant functional impairment and disability. ${ }^{21,22}$ This study recorded that the prevalence of OCD in the studied participants was $3.24 \%$ (51 out of 1574)

Table (3): Binary logistic regression model for the predictors of OCD:

\begin{tabular}{lcccc}
\hline \multicolumn{1}{c}{ Variable } & Wald & Sig & Exponential $\boldsymbol{\beta}$ & 95\% CI \\
\hline $\begin{array}{l}\text { Residence } \\
\text { Urban Vs rural* }\end{array}$ & 0.47 & 0.49 & 1.57 & $0.213-11.63$ \\
\hline $\begin{array}{l}\text { Socioeconomic status } \\
\text { High Vs middle and low * }\end{array}$ & 3.61 & 0.057 & 2.14 & $1.38-3.32$ \\
\hline $\begin{array}{l}\text { Positive family history } \\
\text { Present Vs absent* }\end{array}$ & 6.79 & 0.009 & 3.89 & $1.72-8.79$ \\
\hline $\begin{array}{l}\text { Presence of close friends } \\
\text { Absent Vs present* }\end{array}$ & 0.079 & 0.779 & 0.286 & $0.078-1.08$ \\
\hline $\begin{array}{l}\text { PIQ } \\
\text { Low Vs high* }\end{array}$ & 5.31 & 0.021 & 1.59 & $0.92-2.75$ \\
\hline *Reference group & & & &
\end{tabular}

and this was in agreement with Diler and Avci who done a similar study in the Southeastern United States and Turkey and found that the prevalence of OCD was $2.7 \%^{23}$, But Bryńska and Wolańczyk, and Jaisoorya et al., in Poland and India recorded that the prevalence was $1 \%$ and $0.8 \%$ respectively. ${ }^{24,} 25$ The difference in prevalence from country to the other may be due to difference in culture or in methodology.

On comparing cases with controls, there was non-significant difference regarding age and sex which was in consistency with Motawa et al., who carried a study to assess the prevalence of OCD in patients with dermatological disorders attending Mansoura University Hospital and stated that there was no significant difference between the OCD group and the rest of the studied group regarding age and sex. ${ }^{(26)}$ Also, Diler and Avci and Canals et al., who done study on the epidemiology of OCD in Spanish school children found that there was no significant relation as regarding $\operatorname{sex}^{23,6}$, but Jaisoorya et al., reported that males were more affected than females in their studies. $^{25}$

Urban residence was significantly associated with OCD cases than the controls in the current study; this was in agreement with Motawa et al., who found that urban residence is significantly associated with OCD group. ${ }^{26}$ Also, Rintala et al., in Finland reported that subjects born in urban areas had significantly elevated rates of OCD compared to those born in semi-urban or rural area (OR 1.42, 95\% CI 1.26-1.61, $p<0.001) .{ }^{27}$ High socioeconomic level was significantly related to OCD cases in the current study. This was in accordance with Rintala et al., who reported high prevalence of OCD cases among high socioeconomic status ${ }^{27}$, this contrasted with Vasudev et al., in India who conducted a study to assess the Quality of Life (QOL) in OCD and found no significant statistical difference between high and low socioeconomic levels. ${ }^{28}$ Also, Heyman et al., reported that children with OCD were more likely associated with lower socio-economic class. $^{3}$

The current study recorded that positive family history, and the absence of close friends was significantly associated with OCD cases. This was in accordance with Fontenelle and Hasler who found that OCD was a familial disorder. ${ }^{29}$ Also, Timpano et al. reported that OCS had a significant association with the social isolation and loneliness ${ }^{30}$ Similarly, 
Chmielewski and Watson found that the OCD cases had no close friends. ${ }^{31}$

This study stated that there was nonsignificant difference between OCD cases and control regarding birth order and family size and this agreed with Diler and Avci who found that there was no difference between firstborn and other children in a family ${ }^{23}$ but Heyman et al., 2001 found that OCD was significantly higher in children with large family size. ${ }^{3}$

This current study stated that there was non-significant difference between OCD cases and control regarding smoking, traumatic life event, parental conflicts, and drug abuse. Abramovitch et al, reported that decreased smoking rate among OCD subjects was confirmed. ${ }^{12}$ Brakoulias et al., in Australian cities recorded that patients with OCD were associated with post-traumatic stress and substance use disorders. ${ }^{32}$ Fontenelle and Hasler stated that those who are abusing drugs are more likely to present with OCD. ${ }^{(29)}$ Cromer et al., and Landau et al., reported that traumatic life events increase severity of OCD symptoms. ${ }^{33,34}$ Non-significant difference was observed in this study between cases and control regarding full scale IQ score and verbal IQ but the performance IQ show significant difference between the two groups which may be due to decreased processing speed in OCD patients. This agreed with Batistuzzo et al., who stated that there no differences were found on the full-scale IQ or verbal IQ. ${ }^{35}$ In contrast, a significant difference was found in the performance IQ. A pioneer meta-analysis in adults (98 studies, $\mathrm{n}=1180$ ) published by Abramovitch et al., intended to better clarify the IQ pattern in adults with OCD in comparison to healthy controls. The authors reported that adults with OCD were characterized by lower full-scale IQ as compared to healthy controls. Although the subjects with OCD had a mean IQ in the normative range, their verbal IQ and performance IQ presented small and moderate effect sizes (respectively), indicating reduced IQ in patients. $^{36}$

\section{Recommendations}

Based on the findings it is recommended to implement mental health education programs with stress on increasing awareness among teachers, students, and parents. It is important to carry out periodic screening of adolescent for early detection of OCD cases and to provide help and support for cases.

\section{References}

1. Alvarenga $\mathrm{G}$, Cesar C, Leckman $\mathrm{F}$, Moriyama S, Torres $\mathrm{R}$, Bloch $\mathrm{H}$, et al. Obsessive-compulsive symptom dimensions in a population-based, cross-sectional sample of school-aged children. Journal of Psychiatric Research, 2015; 62, 108-114.

2. American Psychiatric Association. Diagnostic and Statistical Manual of Mental Disorders (DSM-5). 5th ed. Arlington: American Psychiatric Publishing; 2013.

3. Heyman I, Fombonne F, Simmons H, Ford T, Meltzer H, Goodman R. Prevalence of obsessive-compulsive disorder in the British nationwide survey of child mental health. The British Journal of Psychiatry, 2001; 179, 324-329.

4. Yoldascan E, Ozenli Y, Kutlu O, Topal K, Bozkurt AI. Prevalence of obsessivecompulsive disorder in Turkish university students and assessment of associated factors. BMC Psychiatry. 2009; 9:40.

5. American Academy of Child and Adolescent Psychiatry (AACAP). Practice parameters for the assessment and treatment of children and adolescents with obsessive. $\mathbf{J}$ Am Acad Child Adolesc Psychiatry 2012; 51(1):98-113.

6. Canals J, Hernandez-Martinez C, Cosi S, \& Voltas N. The epidemiology of obsessivecompulsive disorder in Spanish school children. Journal of Anxiety Disorders, 2012; 26, 746-752.

7. Valderhaug R, Ivarsson T. Functional impairment in clinical samples of Norwegian and Swedish children and adolescents with obsessive compulsive disorder. Eur Child Adolesc Psychiatry. 2005; 14:164-73. 
8. Piacentini J, Bergman RL, Keller M, McCracken J. Functional impairment in children and adolescents with obsessivecompulsive disorder. J Child Adolesc Psychopharmacol. 2003; 13 Suppl 1:S61-9.

9. Heyman I, Fombonne E, Simmons H, Ford T, Meltzer H, Goodman R. Prevalence of obsessive-compulsive disorder in the British nationwide survey of child mental health. International Review of Psychiatry, $2003 ; 15,178-184$.

10.Geller D A, March J. Practice parameter for the assessment and treatment of children and adolescents with obsessive-compulsive disorder. Focus, 2012; 10, 360-373.

11.Iniesta-Sepulveda M, Rosa-Alcazar AI, Rosa-Alcazar A, Storch EA. Evidence-based assessment in children and adolescents with obsessive-compulsive disorder. Journal of Child and Family Studies, 2014; 23, 14551470.

12. Abramovitch A, Abramowitz JS, Mittelman A, Stark A, Ramsey K, Geller DA. Research Review: Neuropsychological test performance in pediatric obsessivecompulsive disorder- a meta-analysis. Journal of Child Psychology and Psychiatry, 2015; 56(8), 837-847.

13.Barzilay R, Patrick A, Calkins ME, Moore TM, Wolf DH, Benton TD, et al. Obsessive-Compulsive Symptomatology in Community Youth: Typical Development or a Red Flag for Psychopathology? Journal of the American Academy of Child \& Adolescent Psychiatry, 2018; (58) 2, 277286. 15.

14.El-Gilany A, El-Wehady A, El-Wasify M - Updating and validation of the socioeconomic status scale for health research in Egypt. East Mediterr Health J,2012; 18: 962-968.

15.Okasha A, Saad A, Khalil AH, El Dawla AS, Yehia N. phenomenology of obsessivecompulsive disorder: a transcultural study. Comper psychiatry, 1994; 35:191-197.

16.Goodman WK, Price LH, Rasmussen SA, Mazure C, Fleischmann RL, Hill CL, et al. The Yale-Brown Obsessive Compulsive Scale. I. Development, use, and reliability. Arch Gen Psychiatry 1989; 46:1006-1011. 17. Kim SW, Dysken MW, Kuskowski M. The Yale-Brown Obsessive-Compulsive Scale: A reliability and validity study. Psychiatry Research 1990; 34:99-106.
18. Abdel- Khalek AM. The development and validation of the Arabic ObsessiveCompulsive scale. European journal of Psycological Assessment 1998; 14(2), 146158.

19.Ismail ME, Melika LK. Wechsler Intelligence Scale for Children: Arabic Manual,7th ed. Cairo, Egypt: El-Nahda Press, 1999.

20.Wechsler D. Wechsler Adult Intelligence Scale (4th Ed.). San Antonio, TX: Pearson Assessment, 2008. https://doi.org/10.1037/t15169-000.

21.Torres AR, Prince MJ, Bebbington PE, Bhugra D, Brugha T S, Farrell M, et al. Obsessive-compulsive disorder: prevalence, comorbidity, impact, and help-seeking in the British National Psychiatric Morbidity Survey of 2000. American Journal of Psychiatry, 2006; 163(11), 1978-1985.

22. Markarian Y, Larson MJ, Aldea M A, Baldwin S A, Good D, Berkeljon A, McKay D. Multiple pathways to functional impairment in obsessive-compulsive disorder. Clinical psychology review, 2010; 30(1), 78-88.

23.Diler RS, Avci A. Sociodemographic and clinical characteristics of Turkish children and adolescents with obsessive-compulsive disorder. Croatian medical journal,2002; 43(3), 324-329.

24.Jaisoorya TS, Reddy YJ, Thennarasu K, Beena $\mathrm{K} \mathrm{V}$, Beena $\mathrm{M}$, Jose $\mathrm{D}$ C. An epidemological study of obsessivecompulsive disorder in adolescents from India. Comprehensive psychiatry, 2015; 61, 106-114.

25.Bryńska A, Wolańczyk T. Epidemiology and phenomenology of obsessivecompulsive disorder in non-referred young adolescents. European child \& adolescent psychiatry, 2005; 14(6), 319-327.

26. Motawa, SS, Fayed HAER, Abdelaziz A, Elsaadouni N, Elwasify M. Prevalence of obsessive-compulsive spectrum disorder in patients seeking dermatological consultation. Egyptian Journal of Psychiatry, 2020; 41(2), 97.

27.Rintala H, Chudal R, Leppämäki S, Leivonen S, Hinkka-Yli-Salomäki S, Sourander A. Register-based study of the incidence, comorbidities and demographics of obsessive-compulsive disorder in specialist healthcare. BMC psychiatry, 2017; 17(1), 64.
No. 4

Oct. 2021 
28. Vasudev R G, Yallappa S C, Saya G K. Assessment of quality of life (QOL) in obsessive compulsive disorder (OCD) and dysthymic disorder (DD): a comparative study. Journal of Clinical and Diagnostic Research, 2015; 9(5), V0-4.

29.Fontenelle LF, Hasler G. The analytical epidemiology of obsessive-compulsive disorder: risk factors and correlates. Progress in Neuro-Psychopharmacology and Biological Psychiatry, 2008; 32(1), 1-15.

30.Timpano KR., Çek D, Rubenstein LM, Murphy D, Schmidt NB. Exploring the association between obsessive-compulsive symptoms and loneliness: Consideration of specificity and gender. Journal of Cognitive Psychotherapy, 2014, 28(4), 264-273.

31.Chmielewski M, Watson D. The heterogeneous structure of schizotypal personality disorder: Item-level factors of the schizotypal personality questionnaire and their associations with obsessive-compulsive disorder symptoms, dissociative tendencies, and normal personality. Journal of Abnormal Psychology, 2008; 117(2), 364-376.

32.Brakoulias V, Starcevic V, Berle D, Milicevic D, Hannan A, Viswasam K, et al.
The clinical characteristics of obsessivecompulsive disorder associated with high levels of schizotypy. Australian \& New Zealand Journal of Psychiatry, 2014; 48(9), 852-860.

33. Cromer KR, Schmidt NB, Murphy DL. Do traumatic events influence the clinical expression of compulsive hoarding? Behaviour research and therapy, 2007; 45(11), 2581-2592.

34.Landau D, Iervolino, AC, Pertusa A, Santo S, Singh S, Mataix-Cols D. Stressful life events and material deprivation in hoarding disorder. Journal of anxiety disorders, 2011; 25(2), 192-202.

35.Batistuzzo MC, Souza MD, Bernardes ET, Requena G, Miguel EC, Shavitt RG. Intelligence Quotient (IQ) in Pediatric Patients with Obsessive-Compulsive Disorder. Journal of Obsessive-Compulsive and Related Disorders, 2020; 100548.

36. Abramovitch A, Anholt G, RavehGottfried S, Hamo N, Abramowitz JS. Metaanalysis of intelligence quotient (IQ) in obsessive-compulsive disorder. Neuropsychology Review, 2017; 28(1), 111120. 